\title{
COVID-19 Pandemi Döneminin Özel Gereksinimli Çocuk Annelerinde Anksiyete ve Yaşam Kalitesi Üzerine Etkisinin İncelenmesi
}

\author{
Feride YARAR 國, Seda BAYRAMOĞLU in $^{2}$, Hande ŞENOL 國 ${ }^{3}$
}

Öz

Amaç: COVID-19, ilk olarak Çin'de solunum yolu belirtileri gelişen bir grup hastada yapılan araştırmalar sonucunda tanımlanan bir virüstür. Bu çalışma, COVID-19 pandemi döneminin özel gereksinimli çocuk annelerinde anksiyete ve yaşam kalitesi üzerindeki etkisini incelemek amacıyla planlanmıştır.

Gereç ve Yöntemler: Özel gereksinimli çocuğu olan, yaş ortalaması 39,3 $\pm 8,94$ y1l olan 87 anne çalışmaya dahil edildi. Çalışmada demografik veri formu, COVID-19 ve pandemi dönemine ait hazırlanan soru formu, Nottingham Sağlık Profili (NSP) ve Beck Anksiyete Ölçeği (BAÖ) kullanılmıştır.

Bulgular: Annelerin \%83,9'u (n=73) COVID-19 hakkında bilgisinin olduğunu, \%57,5'i (n=50) çocuklarının ruh sağlığının bu süreçten etkilenmediğini ve $\% 63,2$ 'si $(n=55)$ kendi ruh sağliklarının bu süreçte etkilendiğini ancak $\% 60,9^{\prime}$ u (n=53) bu süreçte anne olarak kendini tükenmiş hissetmediğini bildirmiştir. Çocuğun ruh sağlı̆ğ ile annenin NSP alt parametresi olan sosyal izolasyon puanı arasında anlamlı fark bulunmuştur. Annenin ruh sağlığı ile NSP alt parametresi olan emosyonel reaksiyon ve sosyal izolasyon puanları arasında anlamlı fark bulunmuştur. Annenin tükenmişlik durumu ile NSP alt parametresi olan emosyonel reaksiyon, uyku, sosyal izolasyon, NSP toplam ve BAÖ puanları arasında anlamlı fark bulunmuştur.

Sonuç: COVID-19 özel gereksinimli çocuğa sahip annelerin anksiyete ve yaşam kalitelerini etkilemektedir. Bu nedenle literatürde bu alanda daha geniş popülasyonların dahil edildiği çalışmalara ihtiyaç vardır.

Anahtar Kelimeler: COVID-19; özel gereksinimli çocuk; anne; anksiyete; yaşam kalitesi.

\section{Examining of the Effect of COVID-19 Pandemic Period on Anxiety and Quality of Life in Mother of Children with Special Needs}

\begin{abstract} on anxiety and quality of life in mothers of children with special needs. Health Profile (NHP) and Beck Anxiety Inventory (BAI) were used. sleep, social isolation, NHP T, BAI scores has been found. studies with larger participation are needed in this field in the literature.

Keywords: COVID-19; children with special need; mother; anxiety; quality of life

1 Pamukkale Üniversitesi, Fizik Tedavi ve Rehabilitasyon Yüksek Okulu, Denizli, Türkiye

2 Pamukkale Üniversitesi Sağıı Bilimleri Enstitüsü, Fizik Tedavi ve Rehabilitasyon Anabilim Dalı, Denizli, Türkiye

3 Pamukkale Üniversitesi, Tıp Fakültesi, Biyoistatistik Anabilim Dalı, Denizli, Türkiye

Sorumlu Yazar / Corresponding Author: Feride YARAR, e-mail: fyarar@pau.edu.tr Geliş Tarihi / Received: 01.02.2021, Kabul Tarihi / Accepted: 28.05.2021
\end{abstract}

Aim: COVID-19 is a virus that was first identified as a result of research conducted in a group of patients who developed respiratory symptoms in China. This study was planned to examine the effect of COVID-19 pandemic period

Material and Methods: Eighty-seven mothers with children with special needs and mean age $39.3 \pm 8.94$ yr were included in the study. Demographic data form, question form prepared for COVID-19 pandemic period, Nottingham

Results: $83.9 \%(n=73)$ of the mothers had information about COVID-19, 57.5\% $(n=50)$ of them stated that their children's mental health was'nt affected by this process and $63.2 \%(n=55)$. However, 60.9\% $(n=53)$ reported that their health was affected during this process, but didn't feel exhausted during this period. There was a significant difference between the child's mental health and the mother's social isolation score, which is NHP sub-parameter. A significant difference was found between the mother's mental health and the NHP sub-parameter, emotional reaction and social isolation scores. Significant difference between the mother's burnout status and NHP sub-parameter emotional reaction,

Conclusions: COVID-19 affects the anxiety and quality of life of mothers with children with special needs. Therefore, 


\section{GíRIS}

Çin'in Wuhan şehrinde 31 Aralık 2019'da nedeni bilinmeyen pnömoni vakaları bildirilmiş ve 7 Ocak 2020'de Dünya Sağlık Örgütü (DSÖ) etkeni, önceden insanlarda tespit edilmemiş yeni bir koronavirüs (2019$\mathrm{nCoV}$ ) olarak tanımlamıștır. Daha sonra 2019-nCoV hastalığının adı COVID-19 olarak kabul edilmiştir $(1,2)$. DSÖ, COVID-19 salgınını 30 Ocak'ta “uluslararası boyutta halk sağlığı acil durumu" olarak sınıflandırmış ve Çin'den sonra 113 ülkede COVID-19 vakalarının görülmeye başlanması, vaka sayısındaki hızlı artış nedeniyle 11 Mart'ta küresel salgın (pandemi) olarak tanımlamıştır (3). Ülkemizde ilk vaka 11 Mart'ta görülmüştür (4). Küresel COVID-19 salgını, genel nüfus ve aileler üzerinde ruh sağlığı için önemli zorluklar oluşturarak bir dizi sorunu beraberinde getirmektedir (5). COVID-19'un bireylerin, özellikle de çocukların ruh sağlığını etkilediği yapılan çalışmalarda gösterilmiştir (6). Pandemi çocuklarda okulların kapanması, arkadaşlarıyla görüşememe ve açık havada aktivite yapamama gibi zorluklara neden olmuştur (7). Çin'de çocuklar ve ergenlerde yapılan araştırmalar sonucunda, her birinde yaklaşık \%20 oranında, sinirlilik, korku, depresyon ve anksiyete semptomları bulunmuştur (8). Evden veya esnek çalışma, çocukların evde eğitim görmesi, çocukları evde güvende tutma kaygısı, sosyal hayatlarının kısıtlanması nedeniyle sorumluluklarının artması ebeveynleri olumsuz etkilenmiştir (9) Çin'de yaşayan yetişkinlerin yaklaşık üçte ikisi COVID-19 pandemisi sırasında anormal düzeyde anksiyete yaşadığını bildirmiştir (10).

Özel gereksinimli çocukların ve ailelerinin, COVID-19 sırasında normal olarak gelişen çocukların ailelerine göre daha fazla ruhsal sağlık sorunu yaşama riski altında olduklarına dair kanıtlar vardır (11). Çünkü özel gereksinimli çocuk ebeveynleri normal olarak gelişmiş çocukların ebeveynlerine göre daha fazla zorluklarla karşı karşıya kalmaktadır (12). COVID-19'un bulaşmasını önlemek için en iyi strateji sosyal mesafeyi korumak ve evde kalmak çocuklar için önerilen en etkili yöntemdir (13). Ancak evde kalmak, özel gereksinimli çocukların geliştirilmiş rutinlerinin bozulması, düzenli eğitimin ve/veya fizyoterapinin kesilmesi, pandeminin etkilerinin anlaşılamaması, yeni koşullara uyum sağlayamama; ebeveynlerden eğitimli kişilerin herhangi bir eğitim almadan zor yerine getirdiği rehabilitasyon görevini üstlenmeleri, çocuğun ilerlemesinde gecikme algısı, pandemi nedeniyle ekonomik kisıtlamaların yanı sıra iyileştirici hizmetlere erişememe, özel gereksinimli çocuklar ve aileleri için stresli durum yaratmaktadır $(11,14)$.

Ebeveynler genellikle zamanlarının çoğunu çocuklarıyla geçirirler ve bu nedenle, özel tıbbi veya diğer ihtiyaçlarını karşılamak, çalışmak, diğer çocukların ihtiyaçlarını karşılamak veya sadece dinlenmek için birilerinden yardım istemeleri gerekir ancak bu isteklerini gerçekleştirmek için firsatları çok azdır veya hiç yoktur. En önemlisi, çocukların yeni koşullara alışma çabaları ve tepkileri, ebeveynler için en güçlü stres kaynağı olabilir (15). Özel gereksinimli çocuklar genellikle günlük rutinlerindeki değişikliklere karşı hassastırlar ve çoğu, davranışsal sorunlara sebep olabilecek yüksek düzeyde anksiyete ve huzursuzluk yaşayabilirler. Yapılan araştırmalar, özel gereksinimli çocukların olumsuz davranışlarının ebeveyn stresi ile pozitif yönde ilişkili olduğunu göstermiştir (16). Pandemi sırasında günlük yaşamlarının bu yönündeki herhangi bir bozulma, ebeveynlerin iyilik hallerinin azalmasına ve yüksek anksiyete, depresyon seviyelerine neden olabilir (15).

Ruh sağlığı, yaşam kalitesi açısından bireylerin kişisel ve sosyal işleyişini doğrudan etkiler ve dolayısıyla sosyal ve ekonomik bakım yükleriyle de ilişkilendirilebilir (17). Yaşam kalitesi, DSÖ’ye göre, bireylerin yaşadıkları kültür ve değer sistemleri bağlamında; hedefleri, beklentileri, standartları ve anksiyeteleri ile bağlantılı olarak hayattaki konumlarının algılanmasıdır. Kişinin fiziksel sağlığını, psikolojik durumunu, bağımsızlık düzeyini, sosyal ilişkilerini, kişisel inançlarını ve çevrenin göze çarpan özellikleriyle ilişkisini içeren geniş bir kavramdır (18). Özel gereksinimli çocukların ebeveynleri yüksek stres, değersizlik hissi ve kendini suçlama, bozulmuş fiziksel işlev, yorgunluk veya bitkinlik yaşarlar $(19,20)$. Bu şiddetli kronik koşullara sahip çocukların ailelerinin yaşam kalitesi olumsuz yönde etkilenir (21).

Özel gereksinimli çocuklar, başka ek hastalıklarının olması, normal gelişen bireylere göre daha fazla toplu tedavi ortamlarında bulunmaları, bazılarının önleyici tedbirleri uygulayamaması gibi nedenlerden dolayı hem COVID-19'a yakalanma hem de COVID-19'dan kaynaklanan komplikasyonlar yönüyle genel nüfusa göre daha yüksek risk altındadır (22). İnsanları COVID-19'dan korumak için artan izolasyon, özel gereksinimli çocukların yaşam kalitesi üzerinde olumsuz bir etki oluşturabilir ve olumsuz davranışların artmasına veya yeniden ortaya çıkmasına yol açabilir (22). Çocukların daha yüksek risk altında olması, yaşam kalitelerinin etkilenmesi ve olumsuz davranış sergilemeleri ebeveynlerin anksiyete ve stres düzeylerini artırarak dolaylı olarak ebeveynlerin yaşam kalitesini etkileyebilir (23).

Özel gereksinimli çocukların hayatındaki en etkili insan desteklerinden biri anneleridir. Anneler birincil bakıcıdır ve çocuklarının günlük ihtiyaçlarından, sağlığından, gelişiminden ve aile durumlarının \%95'inden fazlasına katılımından sorumlu kişidir $(24,25)$. Bununla birlikte, özel gereksinimli çocuklara bakan annelerin görevleri en üst düzeyde sağlık gerektirirken, araştırmalar sürekli olarak birçok annenin kötü ruh sağlığı ve/veya yüksek stres bildirdiğini göstermektedir $(26,27)$. Yapılan araştırmalar, özel gereksinimli çocukların annelerinin normal olarak gelişen çocukların annelerine göre klinik olarak önemli düzeyde stres, anksiyete ve depresyon bildirme olasılıklarının iki-üç kat daha fazla olduğunu doğrulamaktadır (28). Anneler genellikle çocukların bakımında yalnızlık, fiziksel ve sosyal sıkıntı yaşarlar, bu durum ve çocukların günlük yaşam aktivitelerindeki bağımlılık seviyeleri annelerin yaşam kalitelerini etkiler. Yapılan çalışmada özel gereksinimli çocuk annelerinin yaşam kalitesi Türk toplum normlarının altında bulunmuştur (23).

Literatürde özel gereksinimli çocuğa sahip olan annelerin daha çoğunlukla ruhsal problemlerle, kas iskelet problemleri ile karşı karşıya kaldığını belirten yayınlar mevcuttur $(15,16,19)$. Pandemi döneminde her anne gibi özel gereksinimli çocuğa sahip olan annelerinde bu 
durumdan ruhsal olarak etkilendiklerini ve yaşam kalitelerinde etkilenebileceğini düşünerek bu çalışmayı planladık. COVID-19 pandemi döneminde özel gereksinimli çocuk annelerinin anksiyete ve yaşam kalitesi üzerindeki etkisini inceleyen çalışma bulunmamaktadır. Çalışmamızın amacı, COVID-19 pandemi döneminin özel gereksinimli çocuk annelerinde anksiyete ve yaşam kalitesi üzerindeki etkisini araştırarak literatüre katkı sağlamaktır.

\section{GEREC VE YÖNTEMLER}

Çalışma Özel Yeni Çağla Pınar Özel Eğitim ve Rehabilitasyon merkezinde eğitim alan ve özel gereksinimli çocuğa sahip annelerin COVID-19 pandemi dönemindeki anksiyete ve yaşam kalitelerinin bu durumdan nasıl etkilendiğini belirlemek amacıyla yaş ortalaması 39,3 $\pm 8,94$ yıl olan 87 anne katıldı. Çalışma öncesinde rehabilitasyon merkezinden gerekli izin alındı. Çalışmaya katılmayı kabul eden annelerden aydınlatılmış onam alındı ve katılımcılara Helsinki Bildirgesi'ne dayanarak çalışma hakkında bilgi verildi. Bu çalışma Pamukkale Üniversitesi Tıp Fakültesi, Girişimsel Olmayan Klinik Araştırmalar Etik Kurulu (12/11/2020 60116787-020/68239) tarafindan onayland. Özel Yeni Çağla Pınar Özel Eğitim ve Rehabilitasyon Merkezi'nden gerekli izin etik kurul onayından sonra yazılı olarak alındı. Tüm katılımcı annelerden çalışma ile ilgili sözlü ve yazılı onay alındı. Tüm katılımcı anneler sosyal mesafe kuralına uygun olarak yüz yüze çalışmaya dahil edildi.

Çalışma Kasım-Aralık 2020 tarihleri arasında Özel Yeni Çağla Pınar Özel Eğitim ve Rehabilitasyon Merkezi'nde gönüllü annelerin katılımı ile gerçekleştirildi. Çalışma Kasım-Aralık 2020 tarihleri arasında kuruma kayıtlı tüm annelere ulaşılarak düzenlendi. Annelerin belirlenmesinde herhangi bir örnekleme yöntemi kullanılmadı ve çalışmaya katılmaya gönüllü olan tüm annelerin katılımı ile gerçekleştirildi. Kuruma kayıtlı 309 öğrenciden 56'sı kuruma tek geldiği için, 42'si iki kardeşin özel gereksinimli olmasından dolayı, 11'inin bakımına yardımcı ikinci bir kişi olduğu için, 4'ünün annesi okuryazar olmadığı için ve 5 'inin annesi çalışmaya katılmak istemediği için dışlandı. 104 anne COVID-19 nedeniyle çocuklarını merkeze göndermek istemedikleri için ulaşılamadı. Sonuç olarak 87 anne çalışmaya dahil edildi.

Dahil etme kriterleri; 18 yaş ve üstü olmak, okuryazar olmak, soruları anlayabilmek, en az 1 tane özel gereksinimli çocuğu olmak, özel gereksinimli çocuğu ile aynı evde yaşamak ve çocuğun birincil bakıcısı olmak, bakıma ihtiyacı olan başka çocuğun olmaması, şiddetli psikososyal bozukluğu olduğuna dair tanısı olmayan anneler dahil edilmiştir. Çalışmaya katılmayı kabul etmeyen, anketleri eksik ya da hatalı dolduran, birden fazla özel gereksinimli çocuğa sahip olan anneler çalışma dışı bırakıldı.

Çalışmaya dahil edilen annelere demografik veri formu, COVID-19 ve pandemi dönemine ait hazırlanan soru formu, Nottingham Sağlık Profili ve Beck Anksiyete Ölçeği'nden oluşan anketler uygulanmıştır.

Demografik Veri Formu: Annenin yaşını, boyunu, kilosunu, eğitim durumunu, mesleğini, çocuk sayısını, bakıma ihtiyacı olan çocuk sayısını ve çocuğun bakımına yardımcı olan birinin varlığını; çocuğun yaşını, boyunu, kilosunu, tanısını, rehabilitasyon süresini ve yardımcı cihaz kullanma durumunu sorgulayan sorulardan oluşmaktadır.

COVID-19 Soru Formu: Kendi oluşturduğumuz COVID-19 Soru Formu 5 sorudan oluşmaktadır. Annelerin COVID-19 hakkında bilgi sahibi olup olmadıkları, özel eğitim kurumlarının kapalı olduğu süreçte çocuklarının ve kendilerinin ruh sağlığının olumsuz etkilenip etkilenmediği, bu süreçte kendilerini tükenmiş hissedip hissetmedikleri ve önerilen kurallara uyup uymadıklarını sorgulayan bir formdur.

Nottingham Sağlık Profili (NSP): Hunt ve ark. (29) tarafından geliştirilen NSP kişinin algıladığı emosyonel, sosyal ve fiziksel sağlık problemlerini ve bu problemlerin normal günlük aktiviteleri etkileme düzeyini ölçen bir genel yaşam kalitesi anketidir. NSP, 2 bölümden oluşmaktadır. Birinci bölüm ağrı, emosyonel reaksiyonlar, uyku, sosyal izolasyon, fiziksel aktivite ve enerji başlıklı altı kategorilerinden oluşur, toplam 38 soru içerir. İkinci bölüm ise sağlık durumu nedeniyle yaşadığı problemleri sorgulayan 7 soru içerir. Bu bölüm isteğe bağlı cevaplandırılır. NSP, toplam puanı 0-600 arasında değişkenlik göstermektedir. Yüksek skor yaşam kalitesinin kötü olmasına işarettir. NSP'nin Türkçe'ye uyarlanması Küçükdeveci ve ark. (30) tarafından yapılmıştır.

Beck Anskiyete Ölçeği (BAÖ): Beck ve ark. (31) tarafından geliştirilen BAÖ bireyin yaşadığı anksiyete belirtilerinin sıklığını değerlendirir. Kendi kendini değerlendirme ölçeği olan BAÖ yirmi bir maddeden oluşur ve her bir madde 0 ile 3 arasında puan alır. Likert tipi ölçüm sağlar. BAÖ’nün toplam puanı 0 ile 63 puan arasında değişmektedir ve yüksek puanlar bireyin yaşadığı anksiyetenin şiddetini gösterir (32). Ölçeğin Türkçe'ye uyarlaması Ulusoy ve ark. tarafindan yapılmıştır.

\section{İstatistiksel Analiz}

Veriler SPSS 25.0 (IBM SPSS Statistics 25 software (Armonk, NY:IBM Corp.)) paket programiyla analiz edilmiştir. Sürekli değişkenler ortalama \pm standart sapma ve en küçük-en büyük değerler, ortanca ve 25. - 75. yüzdelikler (IQR) ile; kategorik değişkenler ise sayı ve yüzde olarak ifade edilmiştir. Verilerin normal dağılıma uygunluğu Kolmogorov Smirnov ve Shapiro Wilk testleri ile incelenmiştir. Bağımsız grup incelemelerinde; Mann Whitney $U$ testi kullanılmıştır. Tüm analizlerde $\mathrm{p}<0,05$ istatistiksel olarak anlamlı kabul edilmiştir.

\section{BULGULAR}

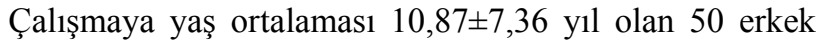
(\%57,5), $27 \mathrm{k}$ ız $(\% 42,5)$ çocuk annesi dahil edilmiştir. Annelerin \%56,3'ü ilkokul mezunu, \%93,1'i (n=81) ev hanımıdır. Annelerin demografik özellikleri Tablo 1'de verilmiştir. Çocukların \%16,1'i $(n=14)$ Serebral Palsi, $\% 14,9$ 'u $(\mathrm{n}=13) \quad$ Otizm, \%11,5'i $\quad(\mathrm{n}=10) \quad$ zihinsel engellidir ve ortalama rehabilitasyon süreleri $84,52 \pm$ 84,02 aydir.

Annelerin \%83,9'u (n=73) COVID-19 hakkında bilgisinin olduğunu, $\% 57,5^{\prime}$ i $(n=50)$ çocuklarının ruh sağlığının bu süreçten etkilenmediğini ve \%63,2'si $(\mathrm{n}=55)$ kendi ruh sağlıklarının bu süreçte etkilendiğini 
ancak \%60,9'u (n=53) bu süreçte kendini tükenmiş hissetmediğini bildirmiştir (Tablo 2). Annelerin NSP toplam puanı 120,14 \pm 104,05 (Min:0 - Max: 463,86) , BAÖ puanı ise 6,6 $\pm 9,61$ (Min: 0 - Max: 48) olarak bulunmuştur.

Tablo 1. Annelerin demografik özellikleri

\begin{tabular}{|l|c|c|}
\hline & Ort \pm S.S. & Med (min - max) \\
\hline Yaş (yıl) & $39,3 \pm 8,94$ & $38(21-64)$ \\
\hline Boy $(\mathbf{c m})$ & $160,82 \pm 6,49$ & $160(148-180)$ \\
\hline Kilo $(\mathbf{k g})$ & $72,78 \pm 13,99$ & $70(45-105)$ \\
\hline BKI $\left(\mathbf{k g} / \mathbf{m}^{2}\right)$ & $28,22 \pm 5,35$ & $28,52(16,71-$ \\
& $7,76 \pm 3,57$ & $39,35)$ \\
\hline Eğitim yılı & $2,41 \pm 1,14$ & $2(1-6)$ \\
\hline Çocuk sayısı & \multicolumn{2}{|c|}{ BKI: Beden Kitle Indeksi, Ort \pm SS: Ortalama \pm Standart Sapma, Med: Medyan Min: }
\end{tabular}

Minimum Max: Maksimum

Annenin COVID-19 bilgisi ile NSP alt parametreleri, NSP toplam puanı ve BAÖ puanı arasında anlamlı fark bulunamamıştır $(p>0,05)$ (Tablo 3-4). Çocuğun ruh sağlığını sorguladığımızda bu durum ile annenin NSP alt parametresi olan sosyal izolasyon puanı arasında anlamlı fark vardır $(p=0,017)$ (Tablo 3). Annenin ruh sağlığını sorguladığımızda NSP alt parametresi olan emosyonel reaksiyon $(\mathrm{p}=0,001)$ ve sosyal izolasyon puanları $(\mathrm{p}=0,015)$ arasında anlamlı fark vardır (Tablo 3$)$.

Tablo 2. Annelerin COVID-19 bilgi formu cevaplar1

\begin{tabular}{|l|c|c|}
\hline & $\begin{array}{c}\text { n (Evet } \\
\text { / Hayır) }\end{array}$ & $\begin{array}{c}\text { \% (Evet / } \\
\text { Hayır) }\end{array}$ \\
\hline $\begin{array}{l}\text { COVID-19 hakkında bilginiz } \\
\text { var mı? (Soru 1) }\end{array}$ & 73 / 14 & 83,9 / 16,1 \\
\hline $\begin{array}{l}\text { Çocuğunuzun ruh sağlığ1 bu } \\
\text { süreçte etkilendi mi? (Soru 2) }\end{array}$ & 37 / 50 & 42,5 / 57,5 \\
\hline $\begin{array}{l}\text { Sizin ruh sağlığınız bu süreçte } \\
\text { etkilendi mi? (Soru 3) }\end{array}$ & $55 / 32$ & 63,2 / 36,8 \\
\hline $\begin{array}{l}\text { Kendinizi bu süreçte tükenmiş } \\
\text { hissettiniz mi? (Soru 4) }\end{array}$ & $34 / 53$ & $39,1 / 60,9$ \\
\hline $\begin{array}{l}\text { Kurallara uyuyor musunuz? } \\
\text { (Soru 5) }\end{array}$ & 87 / 0 & 100 / 0 \\
\hline
\end{tabular}

Annenin ruh sağlığı ile diğer parametreler ve BAÖ arasında anlamlı fark bulunamamıştır $(\mathrm{p}>0,05)$ (Tablo 34). Annenin tükenmişlik durumunu sorguladığımızda NSP alt parametresi olan duygusal reaksiyon $(\mathrm{p}=0.0001)$, uyku $(\mathrm{p}=0,006)$, sosyal izolasyon $(\mathrm{p}=0,001)$, NSP toplam puanı $(\mathrm{p}=0,004)$ ve BAÖ puanları $(\mathrm{p}=0,001)$ arasında anlamlı fark vardır (Tablo 3-4).

Tablo 3. Annelerin COVID-19 bilgi formu cevapları ile NSP puanlarının karşılaştırılması**

\begin{tabular}{|c|c|c|c|c|c|c|c|c|}
\hline & & NSP A & NSP ER & NSP U & NSP Sİ & NSP FA & NSP E & NSP Toplam \\
\hline \multirow{3}{*}{$\begin{array}{l}\text { S } \\
\mathbf{o} \\
\mathbf{r} \\
\mathbf{u} \\
\mathbf{1}\end{array}$} & $\begin{array}{l}\text { Evet } \\
(n=73)\end{array}$ & $\begin{array}{c}5,83 \\
(0-29,44)\end{array}$ & $\begin{array}{c}21,07 \\
(9,76-34,76)\end{array}$ & $\begin{array}{c}0 \\
(0-39,83)\end{array}$ & $\begin{array}{c}0 \\
(0-22,27)\end{array}$ & $\begin{array}{c}9,3 \\
(0-21,77)\end{array}$ & $\begin{array}{c}36,8 \\
(0-60,8)\end{array}$ & $\begin{array}{c}91,23 \\
(54,52-168,9)\end{array}$ \\
\hline & $\begin{array}{l}\text { Hayır } \\
(n=14)\end{array}$ & $\begin{array}{c}4,48 \\
(0-31,3)\end{array}$ & $\begin{array}{c}14,01 \\
(5,31-36,21)\end{array}$ & $\begin{array}{c}17,47 \\
(0-51,93)\end{array}$ & $\begin{array}{c}0 \\
(0-36,95)\end{array}$ & $\begin{array}{c}0 \\
(0-13,9)\end{array}$ & $\begin{array}{c}30,4 \\
(0-39,2)\end{array}$ & $\begin{array}{c}103,41 \\
(43,27-154,46)\end{array}$ \\
\hline & $\mathrm{p}^{*}$ & $\begin{array}{c}0,927 \\
(z=-0,092)\end{array}$ & $\begin{array}{c}0,646 \\
(z=-0,459)\end{array}$ & $\begin{array}{c}0,292 \\
(z=-1,055)\end{array}$ & $\begin{array}{c}0,579 \\
(z=-0,555)\end{array}$ & $\begin{array}{c}0,48 \\
(\mathrm{z}=-0,707)\end{array}$ & $\begin{array}{c}0,79 \\
(z=-0,266)\end{array}$ & $\begin{array}{c}0,963 \\
(z=-0,046)\end{array}$ \\
\hline \multirow{3}{*}{$\begin{array}{l}S \\
\mathbf{o} \\
\mathbf{r} \\
\mathbf{u} \\
\mathbf{2}\end{array}$} & $\begin{array}{l}\text { Evet } \\
(n=37)\end{array}$ & $\begin{array}{c}8,96 \\
(0-44,19)\end{array}$ & $\begin{array}{c}22,48 \\
(10,47-42,39)\end{array}$ & $\begin{array}{c}12,57 \\
(0-41,6)\end{array}$ & $\begin{array}{c}15,97 \\
(0-40,43)\end{array}$ & $\begin{array}{c}11,2 \\
(0-21,99)\end{array}$ & $\begin{array}{c}36,8 \\
(0-60,8)\end{array}$ & $\begin{array}{c}111,66 \\
(58,67-201,14)\end{array}$ \\
\hline & $\begin{array}{l}\text { Hayır } \\
(n=50)\end{array}$ & $\begin{array}{c}2,92 \\
(0-24,48)\end{array}$ & $\begin{array}{c}17,2 \\
(5,31-33,09)\end{array}$ & $\begin{array}{c}0 \\
(0-39,83)\end{array}$ & $\begin{array}{c}0 \\
(0-19,55)\end{array}$ & $\begin{array}{c}0 \\
(0-11,2)\end{array}$ & $\begin{array}{c}24 \\
(0-36,8)\end{array}$ & $\begin{array}{c}78,17 \\
(43,15-127,86)\end{array}$ \\
\hline & $\mathrm{p}^{*}$ & $\begin{array}{c}0,336 \\
(\mathrm{z}=-0,962)\end{array}$ & $\begin{array}{c}0,171 \\
(\mathrm{z}=-1,368)\end{array}$ & $\begin{array}{c}0,707 \\
(z=-0,376)\end{array}$ & $\begin{array}{c}0,017 \\
(\mathrm{z}=-\mathbf{2 , 3 9 4})\end{array}$ & $\begin{array}{c}0,059 \\
(\mathrm{z}=-1,885)\end{array}$ & $\begin{array}{c}0,191 \\
(z=-1,307)\end{array}$ & $\begin{array}{c}0,144 \\
(z=-1,46)\end{array}$ \\
\hline \multirow{3}{*}{$\begin{array}{l}\mathbf{S} \\
\mathbf{0} \\
\mathbf{r} \\
\mathbf{u} \\
\mathbf{3}\end{array}$} & $\begin{array}{l}\text { Evet } \\
(n=55)\end{array}$ & $\begin{array}{c}5,83 \\
(0-22,9)\end{array}$ & $\begin{array}{c}24,42 \\
(10,47-45,49)\end{array}$ & $\begin{array}{c}12,57 \\
(0-43,36)\end{array}$ & $\begin{array}{c}0 \\
(0-35,33)\end{array}$ & $\begin{array}{c}10,79 \\
(0-21,77)\end{array}$ & $\begin{array}{c}36,8 \\
(0-60,8)\end{array}$ & $\begin{array}{c}105,51 \\
(54,03-194,86)\end{array}$ \\
\hline & $\begin{array}{l}\text { Hayır } \\
(n=32)\end{array}$ & $\begin{array}{c}9,73 \\
(0-32,36) \\
\end{array}$ & $\begin{array}{c}10,47 \\
(0-29,55) \\
\end{array}$ & $\begin{array}{c}0 \\
(0-39,83) \\
\end{array}$ & $\begin{array}{c}0 \\
(0-0) \\
\end{array}$ & $\begin{array}{c}0 \\
(0-21,67) \\
\end{array}$ & $\begin{array}{c}36,8 \\
(0-38,6)\end{array}$ & $\begin{array}{c}78,17 \\
(38,95-127,53)\end{array}$ \\
\hline & $\mathrm{p}^{*}$ & $\begin{array}{c}0,561 \\
(z=-0,582)\end{array}$ & $\begin{array}{c}\mathbf{0 , 0 0 1} \\
(\mathrm{z}=-\mathbf{3 , 2 4 4})\end{array}$ & $\begin{array}{c}0,481 \\
(z=-0,705)\end{array}$ & $\begin{array}{c}\mathbf{0 , 0 1 5} \\
(\mathrm{z}=-\mathbf{2 , 4 3 4 )}\end{array}$ & $\begin{array}{c}0,18 \\
(\mathrm{z}=-1,342)\end{array}$ & $\begin{array}{c}0,622 \\
(z=-0,493)\end{array}$ & $\begin{array}{c}0,275 \\
(z=-1,092)\end{array}$ \\
\hline \multirow{3}{*}{$\begin{array}{l}S \\
\mathbf{o} \\
\mathbf{r} \\
\mathbf{u} \\
4\end{array}$} & $\begin{array}{l}\text { Evet } \\
(n=34)\end{array}$ & $\begin{array}{c}8,96 \\
(0-46,46) \\
\end{array}$ & $\begin{array}{c}29,41 \\
(17,37-62,89) \\
\end{array}$ & $\begin{array}{c}33,82 \\
(0-65,06) \\
\end{array}$ & $\begin{array}{c}21,07 \\
(0-41,56) \\
\end{array}$ & $\begin{array}{c}10,79 \\
(0-21,46) \\
\end{array}$ & $\begin{array}{c}36,8 \\
(0-82) \\
\end{array}$ & $\begin{array}{c}122,92 \\
(70,83-291,08) \\
\end{array}$ \\
\hline & $\begin{array}{l}\text { Hayır } \\
(n=53)\end{array}$ & $\begin{array}{c}0 \\
(0-25,55)\end{array}$ & $\begin{array}{c}10,47 \\
(3,54-26,66)\end{array}$ & $\begin{array}{c}0 \\
(0-27,26)\end{array}$ & $\begin{array}{c}0 \\
(0-0)\end{array}$ & $\begin{array}{c}0 \\
(0-21,88)\end{array}$ & $\begin{array}{c}24 \\
(0-36,8)\end{array}$ & $\begin{array}{c}73,42 \\
(28,83-122,28)\end{array}$ \\
\hline & $\mathrm{p}^{*}$ & $\begin{array}{c}0,164 \\
(\mathrm{z}=-1,393)\end{array}$ & $\begin{array}{c}0.0001 \\
(\mathrm{z}=-4,141)\end{array}$ & $\begin{array}{c}0,006 \\
(z=-2,741)\end{array}$ & $\begin{array}{c}\mathbf{0 , 0 0 1} \\
(\mathrm{z}=-\mathbf{3 , 3 7 2})\end{array}$ & $\begin{array}{c}0,199 \\
(\mathrm{z}=-1,284)\end{array}$ & $\begin{array}{c}0,154 \\
(z=-1,425)\end{array}$ & $\begin{array}{c}\mathbf{0 , 0 0 4} \\
(\mathrm{z}=-2,906)\end{array}$ \\
\hline
\end{tabular}

NSP: Nottingham Sağlık Profili, NSP A: Ağrı, NSP ER: Emosyonel reaksiyon, NSP U: Uyku, NSP Sí: Sosyal izolasyon, NSP FA: Fiziksel aktivite NSP E: Enerji, p<0,05; z: Mann Whitney U testi 
Tablo 4. Annelerin COVID-19 bilgi formu cevapları ile BAÖ puanlarının karşılaştırılması

\begin{tabular}{|c|c|c|c|}
\hline & & Med (IQR) & $\mathbf{p}^{*}$ \\
\hline \multirow[t]{2}{*}{ Soru 1} & Evet & $3(1-7)$ & \multirow{2}{*}{$\begin{array}{c}0,807 \\
(\mathrm{z}=-0,244)\end{array}$} \\
\hline & Hayır & $3.5(0.75-10,25)$ & \\
\hline \multirow[t]{2}{*}{ Soru 2} & Evet & $4(1-11,5)$ & \multirow{2}{*}{$\begin{array}{c}0,238 \\
(\mathrm{z}=-1,18)\end{array}$} \\
\hline & Hayır & $3(1-6)$ & \\
\hline \multirow[t]{2}{*}{ Soru 3} & Evet & $4(1-11)$ & \multirow{2}{*}{$\begin{array}{c}0,343 \\
(z=-0,948)\end{array}$} \\
\hline & Hayır & $3(0,25-6)$ & \\
\hline \multirow[t]{2}{*}{ Soru 4} & Evet & $5(1,75-17)$ & \multirow{2}{*}{$\begin{array}{c}\mathbf{0 , 0 0 1} \\
(\mathrm{z}=-\mathbf{3}, 24)\end{array}$} \\
\hline & Hayır & $2(0-5)$ & \\
\hline
\end{tabular}

Whitney U testi

\section{TARTISSMA}

Küresel COVID-19 dünyada özellikle yetişkin bireyleri olumsuz şekilde etkilemektedir. Aileler pandemi döneminde daha fazla zorlukla karşı karşıya kalmaktadırlar. Gerek çocukların sağlığı gerekse eğitimleri onları çok zorlamaktadır. Pandemi özellikle uzun zaman süreklilik gösterdiği için ruhsal yönden de problemlere yol açmaktadır. Normal gelişim gösteren çocuğa sahip aileler bu dönemde zorlanırken özel gereksinimli çocuğa sahip olan aileler yaşamlarının neredeyse tamamında birçok problem ile karşı karşıya kalıyorlar. Özel gereksinimli çocukların hayatlarındaki en önemli insan desteği ve birincil bakıcıları genellikle anneleridir (24,25). Özel gereksinimli çocukların ve ailelerinin, COVID-19 sırasında normal olarak gelişen çocukların ailelerine göre daha fazla zorluklarla karşı karşıya kaldıkları için ruhsal sağlık sorunu yaşama riskleri daha yüksektir (11). Literatürde COVID-19 pandemi döneminin özel gereksinimli çocukların ve ebeveynlerinin ruh sağlığı üzerine etkisini inceleyen çalışmalar vardır ancak katılımcıların sadece özel gereksinimli çocuk annelerinden oluştuğu herhangi bir çalışma yoktur. $\mathrm{Bu}$ sebeple çalışmamıza özel gereksinimli çocuk annelerini dahil ettik. Elde ettiğimiz sonuçlara genel anlamda bakarsak annelerden aldığımız yanıtlar ile yaşam kalitelerinin olumsuz yönde etkilendiği sonucuna ulaştık.

Çalışmaya katılan annelerin \%83,9'unun COVID-19 hakkında bilgiye sahip olduğunu tespit ettik. $\mathrm{Bu}$ oran çalışmaya katılan annelerin bu konuda bilinç düzeylerinin yüksek olduğunu göstermektedir. Fakat bu konuda literatürde yapılmış herhangi bir çalışmaya rastlayamadik.

Çocuklarının ruh sağlığının etkilenip etkilenmediğini sorguladığımızda ise anneler, çocukların \%57,5'inin $(n=50)$ ruh sağlığının etkilenmediğini bildirmiştir. Asbury ve arkadaşlarının (11) yaptığı çalışmada ebeveynler, çocukların \%25'inin $(\mathrm{n}=60)$ anksiyete, $\% 5$ 'inin $(n=11)$ stres yaşadığını ve \%7‘ $\operatorname{sinin}(n=18)$ düşük ruh haline sahip olduğunu bildirmiştir. Bizim çalışmamızda annelerin \%42,5'i $(n=37)$ çocukların bu durumdan etkilendiklerini düşünmektedir. Çalışmaya katılan annelerinin bilinç düzeyinin yüksek olmasının bu konu ile ilgili özellikle çocukların üzerinde olumlu bir etki yarattığını düşünmekteyiz.

Çalışmamızda annelere COVID-19 pandemi döneminde ruh sağlıklarının etkilenip etkilenmediği soruldu ve annelerin ruh sağlığının etkilendiği tespit edildi. Birçok çalışmaya göre özel gereksinimli çocuğa sahip annelerin ruh sağlığının COVID-19 öncesinde de etkilendiği bilinmektedir (17,28). Asbury ve arkadaşlarının (11) 2020 yılında yaptıkları çalışmada COVID-19'un özel eğitime ihtiyacı olan çocukların ve ebeveynlerin ruhsal sağlıklarını etkilediği sonucuna varılmıştır. Çalışmamızda annelerin ruh sağlığının bu durumdan etkilendiği ve literatür incelemesi yapıldığında sonuçlarımızın literatür ile paralellik gösterdiği sonucu elde edilmiştir.

Çalışmamızda annelerin ruhsal durumlarının bu durumdan etkilendiğini fakat kendilerini tükenmiş hissetmediklerini tespit ettik. Marchetti ve arkadaşlarının (33) yaptığ 1 çalışmada, katılımcıların \%89'u annelerden oluşmakta ve annelerin \%8,8'inin de özel gereksinimli çocuğu olduğu bildirilmiştir. Anneler bu durumdan tükendiklerini ve yorgunluk hissettiklerini bildirmişlerdir. Bizim ülkemizde annelerin çocuklarına daha korumacı yaklaşması, günlük hayatta çocukla daha ilgili olmaları ve çocukların da daha fazla anneye ihtiyaçlarının olması annenin daha güçlü olmasını gerektirmektedir. Anneler ruhsal olarak etkilendiğini düşünse bile tükenmişlik hissetmemektedirler.

Çalışmamızda annelerin yaşam kaliteleri sorgulandığında çocuğunun ruhsal sağlığının etkilendiğini düşünen annelerin sosyal izolasyon puanları etkilenmeyenlere göre daha yüksek bulundu. $\mathrm{Bu}$ durum annelerin yaşam kalitelerini olumsuz yönde etkilemektedir. Marchetti ve arkadaşlarının (33) yaptığı çalışmada da sonuç olarak zayıf sosyal bağlantılar tespit edilmiş ve bunun sonucunda sosyal izolasyon ve yalnızlık ortaya çıkabileceği bildirilmiştir. Sonuçlarımız literatür ile paralellik göstermektedir.

Annelerin ruhsal sağlıklarındaki değişim yaşam kalitelerini hem emosyonel olarak ve hemde sosyal izolasyon anlamında etkilemektedir. Ancak annelerin yaşam kalitesini sorgulayan bir çalışmaya literatürde rastlayamadık.

Çalışmamızda anneleri tükenmişliklerini yüksek bulmasakta yaşam kalitelerine baktığımızda emosyonel, sosyal izolasyon ve uyku parametreleri etkilenmiştir. Giallo ve arkadaşlarının (34) ve Chu ve Richdale (35) yaptıkları çalışmalarda özürlü çocuk annelerinde uyku kalitesinde, yalnızlık ve stres parametrelerinde ilişkiler tespit etmişlerdir. $\mathrm{Bu}$ anlamda değerlendirdiğimizde COVID-19 sonrasında da annelerin etkilendikleri durumlar benzerlik göstermektedir.

Anneler kendilerini tükenmiş hissetmemelerine rağmen anksiyete semptomları gösterdiklerini tespit ettik. Katılımcıların \%79,5'inin annelerden oluştuğu Dhiman ve arkadaşlarının (36) yaptığı çalışmada anksiyete, depresyon ve stres düzeylerinin Depresyon Anksiyete Stresi Ölçeği (DASS-21) ile değerlendirildiği ve sonuç olarak anksiyete düzeylerini hafif şiddete ki anksiyete bulgusu gösterdiğini bulmuşlardır. $\mathrm{Ng}$ ve arkadaşlarının (37) 2017 yılında yaptığı çalışmada \%16 oranında hafif düzeyde anksiyete tespit edilmiştir. Asbury ve arkadaşlarının (11) yaptığı çalışmada ebeveynler ruh sağlıklarının genellikle anksiyete ve korkunun artmasına neden olduğunu bildirmiştir. Ancak bizim çalışmamızda annenin ruh sağlığı ile annelerin BAÖ puanları arasında anlamlı fark bulunamamıştır. Bizim çalışmamızda da annelerde hafif düzeyde anksiyeteye rastladık bu anlamda sonuçlarımız literatür ile benzerlik göstermektedir. 
Çalışmamızın güçlü yanları; bu dönemde özel gereksinimli çocuğa sahip olan anneler üzerinde yapılan ilk araştırma olması, annelerin bu dönemdeki farkındalıklarını sorgulamak, çalışmanın zayıf yönleri; şartlar gereği katılımcı sayısının az olmasıdır.

Sonuç olarak COVID 19 özel gereksinimli çocuğa sahip annelerin anksiyete ve yaşam kalitelerini etkilemektedir. $\mathrm{Bu}$ alanda yapılacak olan çalışmaların daha fazla olması literatüre hem katkı sağlayacak hem de özel gereksinimli çocuğa sahip annelerin sorunları ve yaşadıkları problemler ile ilgili daha fazla farkındalık oluşturacağını düşünmekteyiz.

\section{Teșekkür}

Özel Yeni Çağla Pınar Özel Eğitim ve Rehabilitasyon Merkezine katkılarından dolayı teşekkür ederiz.

Yazar Katkıları: Fikir/Kavram: F.Y.; Tasarım: F.Y., S.B.; Veri Toplama: S.B.; Analiz ve Yorum: H.Ş.; Literatür Taraması: F.Y.,S.B.; Makale Yazımı: F.Y., S.B.; Eleştirel İnceleme: F.Y., S.B., H.Ş.

\section{KAYNAKLAR}

1. Huang C, Wang Y, Li X, Ren L, Zhao J, Hu Y, et al. Clinical features of patients infected with 2019 novel coronavirus in Wuhan, China. Lancet. 2020; 395(10223): 497-506. https://doi.org/10.1016/S0140-6736(20)30183-5.

2. Zhonghua Liu Xing Bing Xue Za Zhi. The epidemiological characteristics of an outbreak of 2019 novel coronavirus diseases (COVID-19) in China. Epidemiology Working Group for NCIP Epidemic Response, Chinese Center for Disease Control and Prevention 2020; 41(2): 145-51. https://doi.org/10.3760/cma.j.issn.02546450.2020.02.003.

3. World Health Organization. WHO announces COVID-19 outbreak a pandemic 2020. https://www.euro.who.int/en/health-topics/healthemergencies/coronovirus-covid-

19/news/news/2020/3/who-announces-covid-19outbreak-a-pandemic.

4. T.C. Sağlık Bakanlığı Halk Sağlığı Genel Müdürlüğü Bilimsel Danışma Kurulu Çalışması. (2020). Covid-19 (sars-cov-2 enfeksiyonu) genel bilgiler, epidemiyoloji ve tanı rehberi, Ankara.

5. Coyne LW, Gould ER, Grimaldi M, Wilson KG, Baffuto G, Biglan A. First things first: parent psychological flexibility and self-compassion during COVID-19. Behav Anal Pract. 2020; 6(6): 1-7. https://doi.org/10.1007/s40617-020-00435-w.

6. Golberstein E, Wen H, Miller BF. Coronavirus disease 2019 (COVID-19) and mental health for children and adolescents. JAMA Pediatr. 2020; 174(9): https://doi.org/10.1001/jamapediatrics.2020.1456.

7. Fegert JM, Vitiello B, Plener PL, Clemens V. Challenges and burden of the Coronavirus 2019 (COVID-19) pandemic for child and adolescent mental health: A narrative review to highlight clinical and research needs in the acute phase and the long return to normality. Child Adolesc Psychiatry Ment Health. 2020; 12(12): 14-20.
8. Cui Y, Li Y, Zheng Y. Mental health services for children in China during the COVID-19 pandemic: results of an expert-based national survey among child and adolescent psychiatric hospitals. Eur Child Adolesc Psychiatry. 2020; 11(6): 1-6.

9. Prime, H., Browne, D. T., \& Wade, M. Risk and resilience in family well-being during the COVID19 pandemic. The American Psychologist. 2020; 75(5):

631-43. https://doi.org/10.1037/amp00006660.

10. Wang C, Pan R, Wan X, Tan Y, Xu L, Ho CS. et al. Immediate psychological responses and associated factors during the initial stage of the 2019 coronavirus disease (COVID-19) epidemic among the general population in China. Int $\mathbf{J}$ Environ Res Public Health. 2020; 17(5): 1729.

11. Asbury K, Fox L, Deniz E. Kodu A, Toseeb U. How is COVID-19 Affecting the mental health of children with special educational needs and disabilities and their families?. J Autism Dev Disord. 2020; 51(5): $1-9$. https://doi.org/10.1007/s10803-020-04577-2.

12. Goudie A, Narcisse MR, Hall DE, Kuo DZ. Financial and psychological stressors associated with caring for children with disability. Fam Syst Health. 2014; 32(3): 280-90.

13. Saxena R, Saxena SK. Preparing children for pandemics. In: Saxena S. (editor). Coronavirus disease 2019 (COVID-19) medical virology: from pathogenesis to disease control. Springer, Singapore. 2020; 187-98. https://doi.org/10.1007/978-981-15-4814-7_15.

14. Eshraghi AA, Li C, Alessandri M, Messinger DS, Eshraghi RS, Mittal R. et al. COVID-19: overcoming the challenges faced by individuals with autism and their families, Lancet Physiatry. 2020; 7(6): 481-3.

15. Lucic L, Brkljacic T, Brajsa-Zganec A. Effects of COVID-19 related restrictive measures on parents of children with developmental difficulties. J Child Serv. 2020; 15(4): 229-34. https://doi.org/10.1108/JCS-07-2020-0041.

16. Hastings RP. Parental stress and behaviour problems of children with developmental disability. J Intellect Dev Disabil. 2002; 27(3): 149-160.

17. Doré I, Caron J. Sante mentale: concepts, mesures et determinants [mental health: concepts, measures, determinants. Sante Ment Que. 2017; 42(1): 125-45.

18. The world health organization quality of life assessment (WHOQOL): position paper from the World Health Organization. Soc Sci Med. 1995; 41(10): 1403-9.

19. Emerson E. Mothers of children and adolescents with intellectual disability: social and economic situation, mental health status, and the self- assessed social and psychological impact of the child's difficulties. J Intellect Disabil Res. 2003; 47(4): 385-99.

20. Hedov G, Anneren G, Wikblad K. Self-perceived health in Swedish parents of children with down's syndrome. Qual Life Res. 2000; 9(4): 415-22.

21. Mugno D, Ruta L, D'Arrigo VG, Mazzone L. Impairment of quality of life in parents of children 
and adolescents with pervasive developmental disorder. Health Qual Life Outcomes. 2007; 22(5): 1-9. https://doi.org/10.1186/1477-7525-5-22.

22. Alexander R, Ravi A, Barclay H, Sawhney I, Chester V, Malcolm V. et al. Langdon Guidance for the treatment and management of COVID-19 among people with intellectual disabilities. J Policy Pract Intellect Disabil. 2020; 17(3): 256-69.

23. Yıldız A, Tarakcı D, Hajebrahimi F, Mutluay F. Disabled children's functionality and maternal quality of life and psychological status. Pediatr Int. 2016; 58(12): 1291-6. https://doi.org/10.1111/ped.13020. Epub 2016 Jul 27. PMID: 27085099.

24. Crowe T, Florez S. Time use of mothers with school-age children: A continuing impact of a child's disability. Am J Occup Ther. 2006; 60(2): 194-203.

25. Bourke-Taylor H, Pallant JF, Law M, Howie L. Predicting mental health among mothers of schoolaged children with developmental disabilities: the relative contribution of child, maternal and environmental factors. Res Dev Disabil. 2012; 33(6): $\quad$ 1732-40. https://doi.org/10.1016/j.ridd.2012.04.011. Epub 2012 Jun 13. PMID: 22699247.

26. Bailey DB, Golden RN, Roberts J, Ford A. Maternal depression and developmental disability: A critique. Dev Disabil Res Rev. 2007; 13(3): 321-9.

27. Singer G. Meta-analysis of comparative studies of depression in mother's of children with and without developmental disabilities. Am J Ment Retard. 2006; 111: 155-69.

28. Lee J. Maternal stress, well-being, and impaired sleep in mothers of children with developmental disabilities: a literature review. Res Dev Disabil. 2013; 34(11): 4255-73.

29. Hunt SM, McEwen J, McKenna SP. Measuring health stats: a new tool for clinicians and epidemiologists. J R Coll Gen Pract. 1985; 35(273): 185-8.

30. Küçükdeveci AA, McKenna SP, Kutlay S, Gürsel Y, Whalley D, Arasil T. The development and psychometric assessment of the Turkish version of the Nottingham Health Profile. Int J Rehabil Res. 2000; 23(1): 31-38

31. Beck AT, Epstein N, Brown G, Steer RA. An inventory for measuring clinical anxiety: Psychometric Properties.J Consult Clin Psychol. 1988; 56(6): 893-7.

32. Ulusoy M, Şahin N, Erkmen H. Turkish version of beck anxiety inventory: Psychometric properties. Int J Cogn Ther. 1998; 12(2): 163-72.

33. Marchetti D, Fontanesi L, Mazza C, Di Giandomenico S, Roma P, Verrocchio MC. Parenting-related exhaustion during the italian COVID-19 lockdown. J Pediatr Psychol. 2020; 45(10):

1114-23. https://doi.org/10.1093/jpepsy/jsaa093.

34. Giallo R., Wood CE, Jellett R., Porter R. Fatigue, wellbeing and parental self-efficacy in mothers of children with an autism spectrum disorder. Autism.
2011;

17(4):

465-80.

http://dx.doi.org/10.1177/1362361311416830.

35. Chu J, Richdale AL. Sleep quality and psychological wellbeing in mothers of children with developmental disabilities. Res Dev Disabil. 2009; 30(6):

1512-22. http://dx.doi.org/10.1016/j.ridd.2009.07.007.

36. Dhiman S, Kumar Sahu P, Reed WR, Ganesh GS, Goyal RK, Jain S. Impact of COVID-19 outbreak on mental health and perceived strain among caregivers tending children with special needs. Res Dev Disabil. 2020; 107(6): 1-16. https://doi.org/10.1016/j.ridd.2020.103790.

37. Ng F, Trauer $\mathrm{T}$, Dodd $\mathrm{S}$, Callaly $\mathrm{T}$, Campbell $\mathrm{S}$, Berk M. The validity of the 21 -item version of the depression anxiety stress scales as a routine clinical outcome measure. Acta Neuropsychiatr. 2017;19(5): 304-10. https://doi.org/10.1111/j.1601 5215.2007.00217.x. 